\title{
Dual Economy Interlinkage in a Monetary Framework: A Post WTO Perspective
}

\author{
Ranjanendra Narayan Nag \\ St. Xavier's College \\ Bhaskar Goswami \\ M.U.C. Women's College,
}

\begin{abstract}
The objective of the paper is to examine macroeconomic developments of labour surplus economy in terms of a dual economy framework. We attempt to build up a two sector, dependent economy model, which is open to trade flows. We focus on specific forms of openness that a labour surplus economy is subject to, particularly in the transition period. The industrial sector is a non-traded sector which uses an imported intermediate input, while the agricultural sector is a traded sector. An important aspect of the paper is the role of the stock of primary commodity as assets in a financial repressed economy and we study effect of forward looking food price expectations. The different comparative static exercises attempted in this paper clearly demonstrate that the results of the conventional closed economy models of a labour surplus economy can be seriously altered in an open economy setting. The model clearly suggests that short run and long run multiplier effects of shocks, either policy induced or otherwise, are significantly different and hence, short run effects cannot be a very reliable guide to the design of macroeconomic policy. The results obtained in this paper can provide important insights into the nature of industry agriculture interlinkage in transitional, emerging market economics, particularly in the post WTO framework.
\end{abstract}

\footnotetext{
*Corresponding address: Ranjanendra Narayan Nag, P-36, CIT Scheme 6 M (S), Kolkata - 700 054, West Bengal, India, Tel: +91-235-28-229, E-mail: rnnag12@rediffmail.com (C2005-Center for International Economics, Sejong Institution, All Rights Reserved.
} 
- JEL Classification: F41, Q1, Q11

- Key words: Agricultural trade liberalization, Dual economy interlinkage

\section{Introduction}

The motivation behind our paper is derived from the contemporary developments that have a profound bearing on an agriculture dependent dual economy. These developments, to a great extent, can be traced to multilateral trade negotiations under various WTO provisions. One of the great achievements of the Uruguay Round was to bring agricultural policies into the mainstream of GATT discipline. Non-tariff barriers to agricultural imports were tarrified and bound and are scheduled for phased reductions and export subsidies have been reduced, mostly between 1995 and 2000. The UR agreement on agriculture together with the SPS agreement (to limit the use of quarantine restrictions), ensure that agricultural trade would be less chaotic after the formation of the new WTO in 1995. The new rules and obligations eventually have constrained further farm protection growth in both advanced and newly industrialized countries, thereby promising greater continuity and stability to international food markets. Clearly less developed countries with comparative advantage in agricultural products could experience export-led growth. In most of the developing countries, agricultural sector has been experiencing gradual export orientation. Governments in developing countries have been setting up agricultural export zones with a view to boosting agricultural exports. ${ }^{1}$ Analysis of recent developments in the post globalization period requires an open economy macromodel which our paper attempts to provide. A key issue that emerges in the present context is the capacity of agricultural exports to contribute to relaxation of foreign exchange constraint and employment generation in a food constrained economy. The present paper attempts to develop a dependent economy macro model to address this particular issue in terms of analysis of shocks, both policy-induced and structural.

Our paper is distinguished from the existing literature by a number of features. First, the dual economy models frequently used in the mainstream structuralist macroeconomics has explored different dimensions of industry-agriculture

\footnotetext{
${ }^{1}$ It is worth noting that there is no country in the world, which has globalized its agricultural sector in the true sense of the term. However a beginning is expected to be made in the direction of agricultural trade liberalization with the implementation of various provisions of the WTO agreements, especially provisions relating to removal of quantitative restrictions on LDC's agricultural exports.
} 
interlinkage primarily in a closed economy framework. ${ }^{2}$ In the existing literature on structural macroeconomics, agricultural sector is primarily viewed as provider of wage goods to the industrial sector. Though this primitive role of the agricultural sector remains important, the role of agriculture as supplier of foreign exchange acquires a special significance in the post WTO context. ${ }^{3}$ Definitely we need a macromodel to address the foreign exchange contribution of the agricultural sector.

Secondly, in a developing economy where capital markets are imperfectly developed or simply do not exist, food grain stocks constitute a widely used financial asset. ${ }^{4}$ In spite of the undeniable significance of food grain stocks in the context of agrarian economies, very few attempts have been made so far to devise a macro theoretical framework within which questions can consistently be raised about the effects of these stocks. The present paper is a humble attempt in this direction.

Thirdly, the existing literature hardly recognizes the importance of monetary factors in shaping macroeconomic developments in a dual economy. An important exception is the paper by Moutos and Vines (1992), which is a closed economy monetary macromodel of intersectoral interlinkage. We take this paper as our point of departure. More specifically, our paper can be viewed as an open economy extension of the paper by Moutos and Vines. ${ }^{5}$

The plan of the paper is as follows. Section II examines the structural features of a dual economy, which is relevant to our purpose. The model is set out in section III. Section IV offers comparative static exercises. Section V concludes the paper.

\section{Structural Features}

The broad structural features of the model include disaggregating the economy

\footnotetext{
${ }^{2}$ See Rakshit (1982), Taylor (1983,1991), Dutta (1990). An important exception is a recent paper by Nag and Ghosh (2003), which explored open economy dimensions of intersectoral interlinkage.

${ }^{3}$ Many developing countries have been experiencing balance of payment difficulties. This has resulted in foreign exchange constraint in the sense that value of export determines value of import. Foreign exchange constraint can be interpreted as supply constraint provided imports are intermediate inputs in production.
}

${ }^{4}$ Rakshit (1982) has even gone so far as saying that the most important reproducible asset in such economies is the stock of food grains and agricultural raw materials, the money prices of which are subject to intertemporal fluctuations.

${ }^{5}$ The importance of constructing an open economy macromodel has to be related to the contemporary developments in the post liberalization period. 
into two sectors, nature of trade specific to a less developed economy and the role of agricultural goods. Some comments on each of these features are in order.

1. The standard dual economy setting of development macroeconomics is followed in the present paper. The agricultural sector operates under supply constraint, which can be specified in terms of given marketable surplus of food (wage goods). Availability of land emerges as binding constraint on agricultural growth. The potential of further expansion of net sown area is practically non-existing and given the environmental commitments it may further decline. A feeble price response is attributable not only to reasonably fixed land supply but also to lower initial input intensity and crop pattern being governed by agro climatic factors. ${ }^{6}$ Though agricultural production is supply constraint, production in the industrial sector is governed by effective demand and its price is determined by average variable cost.

2. The paper utilizes a dependent economy framework to study the pattern of trade. The non-traded sector is the industrial sector, which operates under fixed coefficient technology. This sector uses labour and imported raw material. Production in the industrial sector is exclusively home market specific. On the other hand, the agricultural sector produces for home market and for sales abroad. Thus agricultural sector is the traded sector in our model. The agricultural export is the only source of foreign exchange reserves.

3. Exchange rate is fixed and the paper ignores capital account transactions. ${ }^{7}$ Hence, any current account surplus leads to quantity adjustment through change in the stock of foreign exchange reserves and money supply. In other words, money supply is endogenously determined.

4. In standard dual economy models, commodity prices equate the flow supply and the flow demand for primary goods. However, we focus on the role of stock of agricultural commodities held as one form of assets. This leads to portfolio balance approach to the study of determination of food price. In the context of our model, we study the effects of forward-looking commodity price expectations. ${ }^{8}$

\footnotetext{
${ }^{6}$ The severity of supply constraint hardly relaxes despite favourable farm price movement in the post WTO situation (Desai, 2002).

${ }^{7}$ The extent of external trade in assets has tended to be more limited in developing than in industrial countries, although this situation has recently begun to change in dramatic fashion for an important group of developing economies. Many developing countries prohibit destabilizing capital inflows/outflows by imposing variety of capital controls. Non-inclusion of capital account transaction is not unjustified. It is worth noting that in contrast to major industrial countries, the vast majority of developing countries have neither adopted fully flexible exchange rates nor joined monetary unions (see Agenor and Montiel, 1999 for detailed empirical evidence on exchange regimes and trade in financial assets in developing countries).
} 


\section{The Model}

We consider an open economy consisting of two sectors: the industrial sector producing commodities under cost determined price and the agricultural sector producing commodities under flexible price. The agricultural sector is the traded sector while the industrial sector is the non-traded sector that uses imported intermediate inputs in its production process. However, we abstract from any change in physical capital stock. The model is given by equations 1 to 6 :

$$
\begin{aligned}
& y=\alpha c\left[\left(P_{f} F\right) / P_{Y}+Y\right]-v r+G \\
& r=k+\dot{P}_{f} / P_{f} \\
& P_{y}=w h+e \cdot a_{m} \\
& w=\bar{w} \\
& M / P_{Y}=a\left[\left(P_{f} F\right) / P_{Y}+Y\right]-l r \\
& \dot{M}=P_{f} X\left(e / P_{f}\right)-e \cdot a_{m} y
\end{aligned}
$$

Equation (1) reflects that the total production of the industrial sector is equal to the sum of private consumption expenditure, investment expenditure and government expenditure. Private consumption on the manufactured good is a constant fraction ' $a$ ' of the total consumption expenditure. Total consumption expenditure is equal to $c\left[\left(P_{f}\right.\right.$ $\left.F) / P_{Y}+Y\right]$, where ' $c$ ' is the marginal propensity to consume and $\left[\left(P_{f} F\right) / P_{Y}+Y\right]$ denotes the real income in terms of manufactured goods. Rest of the industrial production is absorbed by investment expenditure and government expenditure. It is to be noted that investment is sensitive to nominal interest rate.

Unlike manufactured goods, primary commodities are used as a means of storing wealth, along with money and bonds. Equation (2) is based on the assumption of perfect substitutability between bonds and primary commodities. In fact, equation (2) states that the returns on primary commodities and bonds are always brought into equality through arbitrage, where ' $k$ ' reflects the difference between the 'convenience yield' and storage costs of holding primary commodities. ${ }^{9}$

Equation (3) reflects that price is equal to average cost of production, where ' $a_{m}$ ' denotes imported intermediate input per unit of industrial output; ' $e$ ' denotes nominal exchange rate; ' $h$ ' denotes labour coefficient, that is, labour per unit of

\footnotetext{
${ }^{8}$ This is similar to portfolio balance approach to exchange rate determination in an open economy framework with capital account transactions.
}

${ }^{9}$ See Kaldor (1939), Gilbert (1985), Frankel (1986), Moutos and Vines (1992). 
industrial output. ${ }^{10}$

Equation (4) represents the basic feature of a labour surplus dual economy, that is, money wage is exogenously given despite presence of surplus labour.

Equation (5) is the conventional money market equilibrium, where ' $M$ ' is the nominal money supply which has been deflated by the price of manufactured goods in order to obtain the real money balances. Demand for real money balances is function of interest rate and real income measured in terms of manufactured goods.

Equation (6) gives the balance of payment identity in an open economy, namely change in money supply equals current account surplus. The non-traded industrial sector depends on imported inputs and the agricultural sector produces exportable. Any difference between value of export and that of import involves quantity adjustment through change in foreign reserves, stock of high powered money and money supply in a fixed exchange rate regime.

\section{A. Short Run Analysis}

In the short run, we take money supply $(M)$ and price of agricultural commodities $\left(P_{f}\right)$ as given. Equations (1) and (5) determines industrial output $(y)$ and rate of interest $(r)$, while equation (3) solves for industrial price $\left(P_{y}\right)$. From equation (1), we get IS curve while from equation (5) we get LM curve and the intersection between these two curves yield equilibrium industrial output level $(y)$ and interest rate $(r)$.

We consider the following determinant.

Figure 1. Determination of $y$ and $r$.

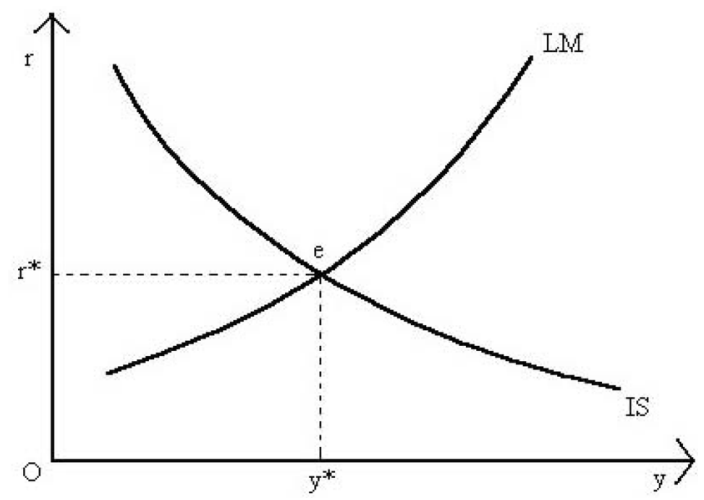

\footnotetext{
${ }^{10}$ Under perfect competition price is equal to average cost. If we introduce market imperfection, price is determined by typical Kaleckian markup formula, which is however, inconsequential in the context of our paper.
} 


$$
|D|=\left|\begin{array}{rr}
(1-\alpha c) v \\
a r
\end{array}\right|=1(\alpha c-1)-a v<0
$$

Now we examine the effects of change in parameters on industrial output level and rate of interest.

1. Change in Money supply : An increase in money supply causes interest rate to fall which leads to rise in investment and industrial output. The effects are given by the following two equations.

$$
\begin{gathered}
\left.\frac{d y}{d M}\right|_{S R}=\frac{-v / P_{y}}{|D|}>0 \\
\left.\frac{d r}{d M}\right|_{S R}=\frac{(1-\alpha c)^{/} P_{y}}{|D|}<0
\end{gathered}
$$

2. Change in Food Price : An increase in food price leads to a rise in real income. Demand for money goes up and interest rate rises to clear money market. Effect on industrial output is ambiguous, since rise in food price causes consumption to rise but investment to fall.

$$
\begin{gathered}
\left.\frac{d y}{d P_{f}}\right|_{S R}=\frac{F[a v-l \alpha c] P_{y}}{|D|} ? \\
\left.\frac{d r}{d P_{f}}\right|_{S R}=\frac{-a \cdot F / P_{y}}{|D|}>0
\end{gathered}
$$

3. Change in Government Expenditure : Rise in government expenditure entails expansion of industrial output, which via money market causes rate of interest to rise.

$$
\begin{aligned}
& \left.\frac{d y}{d G}\right|_{S R}=\frac{-1}{|D|}>0 \\
& \left.\frac{d r}{d G}\right|_{S R}=\frac{-a}{|D|}>0
\end{aligned}
$$

4. Change in Food Supply : Effects of rise in food supply are similar to those of rise in food price. 


$$
\begin{aligned}
& \left.\frac{d y}{d F}\right|_{S R}=\frac{\frac{P_{f}}{P_{y}}[a v-l \alpha c]}{|D|} ? \\
& \left.\frac{d r}{d F}\right|_{S R}=\frac{-a \cdot P_{f} / P_{y}}{|D|}>0
\end{aligned}
$$

5. Change in nominal exchange rate (Devaluation) : Devaluation (an increase in nominal exchange rate) causes industrial price to go up. It reduces real balance and also real demand for money by depressing real income. Hence, effect on rate of interest is ambiguous. However, industrial output unambiguously falls.

$$
\begin{gathered}
\left.\frac{d y}{d e}\right|_{S R}=\frac{F \cdot P_{f} \cdot a_{m} \cdot l \alpha c+a_{m} \cdot v\left[M-a \cdot P_{f} \cdot F\right]}{P_{y}^{2}|D|}<0 \\
\left.\frac{d r}{d e}\right|_{S R}=\frac{\frac{a_{m}}{P_{y}^{2}} \cdot\left[a \cdot P_{f} \cdot F+M(\alpha c-1)\right]}{|D|} ?
\end{gathered}
$$

Since $M>a . P_{f} F$, industrial output always falls. ${ }^{11}$ In what follows we assume that in the short run devaluation causes interest rate to increase.

\section{B. Steady State}

After elimination of ' $y$ ' and ' $r$ ', the system of equations (1) to (6) can be reduced to a system of two differential equations in ' $M$ ' and ' $P_{f}$ '.

$$
\left[\begin{array}{c}
\dot{M} \\
\dot{P}_{f}
\end{array}\right]=\left[\begin{array}{cc}
\theta_{1} & \theta_{2} \\
\Psi_{1} & \Psi_{2}
\end{array}\right]\left[\begin{array}{l}
\bar{M}-M \\
\bar{P}_{f}-P_{f}
\end{array}\right]+\left[\begin{array}{ccc}
\theta_{3} & \theta_{4} & \theta_{5} \\
\psi_{3} & \psi_{4} & \psi_{5}
\end{array}\right]\left[\begin{array}{c}
d G \\
d F \\
d e
\end{array}\right]
$$

where,

$$
\theta_{1}=\frac{d \dot{M}}{d M}=-e \cdot a_{m} \cdot \frac{d Y}{d M}=\frac{+e \cdot a_{m} V}{P_{y \cdot}|D|}<0
$$

$\theta_{2}=x\left[1-e_{x}\right]-e \cdot a_{m} \cdot \frac{d Y}{d P_{f}}<0 \quad$ (Since $e_{x}=$ absolute value of elasticity of export demand $>1$ ).

\footnotetext{
${ }^{11}$ Money market equilibrium requires that $\mathrm{M}=\mathrm{a} \cdot \mathrm{P}_{\mathrm{f}} \cdot \mathrm{F}+\mathrm{a} \cdot \mathrm{P}_{\mathrm{f}} \mathrm{Y}+$ value of speculative demand for money. Clearly $\mathrm{M}>\mathrm{a} . \mathrm{P}_{\mathrm{f} . \mathrm{F}}$. For reasonable small value of $\alpha \mathrm{c},\left.\frac{d r}{d e}\right|_{S R}>0$.
} 


$$
\begin{aligned}
& \psi_{1}=\frac{d \dot{P}_{f}}{d M}=\frac{d r}{d M}<0 . \\
& \psi_{2}=\frac{d \dot{P}_{f}}{d M}=\frac{d r}{d P_{f}}>0 . \\
& \theta_{3}=\frac{d \dot{M}}{d G}=-e \cdot a_{m} \cdot \frac{d Y}{d G}<0 . \\
& \psi_{3}=\frac{d \dot{P}_{f}}{d G}=\frac{d r}{d G}>0 . \\
& \theta_{4}=\frac{d \dot{M}}{d F}=-e \cdot a_{m} \cdot \frac{d Y}{d F} ? \\
& \psi_{4}=\frac{d \dot{P}_{f}}{d F}=\frac{d r}{d F}>0 . \\
& \theta_{5}=\frac{d \dot{M}}{d e}=a_{m} \cdot y\left(e_{x}-1\right)-e \cdot a_{m} \cdot \frac{d Y}{d e}>0 . \\
& \psi_{5}=\frac{d \dot{P}_{f}}{d e}=\frac{d r}{d e}>0 .
\end{aligned}
$$

The determinant of the system is -

$$
\Omega=\theta_{1} \psi_{2}-\theta_{2} \psi_{1}
$$

which is unambiguously negative. As a result, the two characteristic roots of the system are of opposite signs and therefore the system possesses saddle path stability. We assume that food price $\left(P_{f}\right)$ always adjust so as to place the economy on the stable saddle path. ${ }^{12}$

The $\dot{M}$ line shows the combination of money balance and food price consistent with no change in nominal balance, that is, current account balance. The slope of $\dot{M}=0$ line is -

$$
\left.\frac{d P_{f}}{d M}\right|_{\dot{M}=0}=\frac{-\theta_{1}}{\theta_{2}}<0
$$

The line shows the combination of money balance and food price consistent with no change in food price, that is, $r=k$. The slope of $\dot{P}_{f}=0$ line is -

$$
\left.\frac{d P_{f}}{d M}\right|_{\dot{P}_{f}=0}=\frac{-\psi_{1}}{\psi_{2}}>0
$$

\footnotetext{
${ }^{12}$ The derivation of the saddle path is offered in the appendix.
} 
Figure 2. Saddle Path Stability

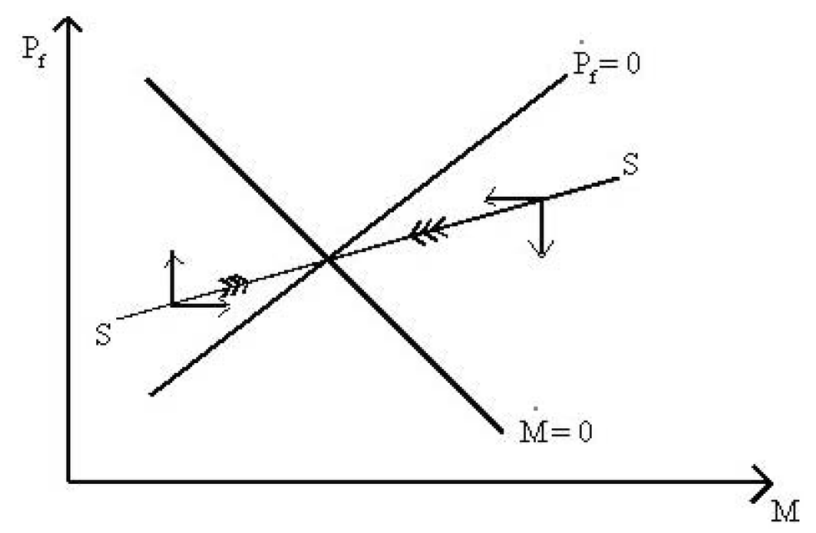

The saddle path is positively sloped and flatter than curve.

\section{Comparative Static Analysis}

1) Increase in Government expenditure : Rise in government expenditure causes industrial output to increase which through money market increases the rate of interest. Interest rate rises to maintain money market equilibrium, leading to $\dot{P}_{f}>0$. Hence, the $\dot{P}_{f}=0$. line shifts downward. Output expansion leads to higher import bill such that $\dot{M}<0$. Hence, $\dot{M}=0$ line also shifts downward. This leads to different possibilities as examined in Fig-3a and Fig-3b.

Initial equilibrium is at point ' $\mathrm{E}_{\mathrm{o}}$ '. Final equilibrium is at point ' $\mathrm{E}_{1}$ '. Food price unambiguously falls but the effect on current account balance and hence money supply is ambiguous. The effects are given by the following equations.

Figure 3a. Undershooting of ' $P_{f}$ '

Figure 3b. Overshooting of ' $P_{f}$ '
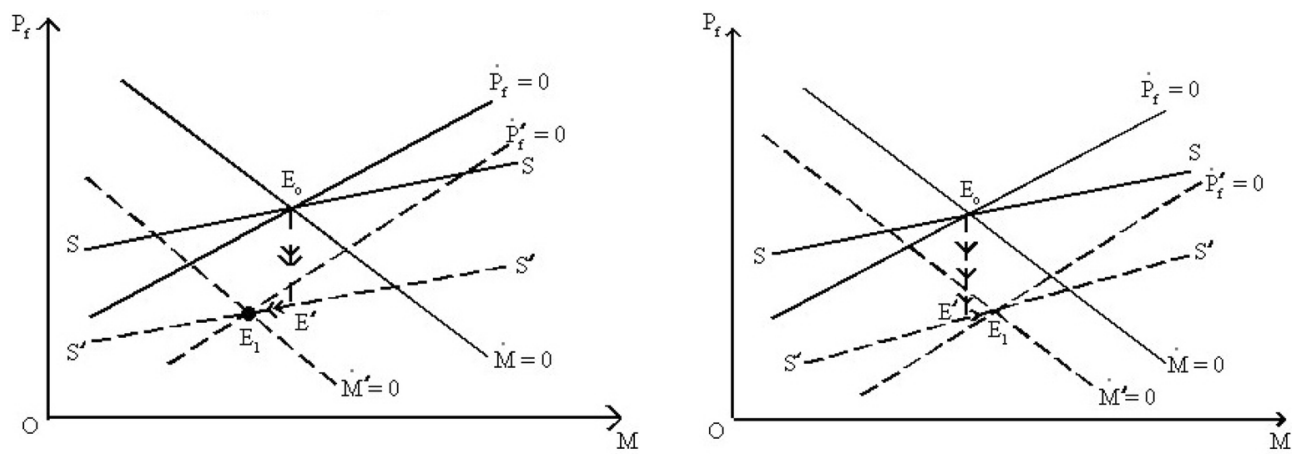


$$
\begin{aligned}
& \left.\frac{d M}{d G}\right|_{L R}=\frac{-\theta_{3} \psi_{2}+\theta_{2} \psi_{3}}{\Omega} ? \\
& \left.\frac{d P_{f}}{d G}\right|_{L R}=\frac{-\theta_{1} \psi_{3}+\theta_{3} \psi_{1}}{\Omega}<0
\end{aligned}
$$

Food price undershoots when money supply falls; it overshoots when money supply increases. The condition for overshooting of food price is -

- $\theta_{3} \psi_{2}+\theta_{2} \psi_{3}<0$. If $-\theta_{3} \psi_{2}+\theta_{2} \psi_{3}>0$, the food price undershoots.

There are two opposite forces working on current account balance. Rise in output tends to generate current account deficit, while fall in food price tends to generate current account surplus (since elasticity of export demand is greater than one). In the short run there is crowding out of private investment through rise in interest rate for any given food price. Since in the long run interest rate is fixed at ' $k$ ', there is no crowding out of private investment. However, we have steady state crowding out of private consumption due to fall in food price which is required to generate additional foreign exchange reserves so as to support the industrial expansion.

2) Increase in food supply : Rise in food supply on impact may either generate expansionary or contractionary effect. But in the long run the effect on industrial output is unambiguously positive and food price falls less than proportionately in response to rise in marketable surplus of food. This result admits of easy economic interpretation. Had there been rise in food price, industrial output would fall to maintain current account balance, but effective demand for industrial output would rise. Clearly this involves contradiction. Now rise in industrial production requires greater availability of foreign exchange which necessitates fall in food price. Again greater demand for industrial output requires less than proportionate fall in food price in response to rise in food supply.

In the short run, rate of interest begins to rise in response to rise in food supply, leading to $\dot{P}_{f}>0$; hence $\dot{P}_{f}=0$ line shifts downward. Short run expansionary effect generates a trade deficit, such that $\dot{M}<0$ and hence $\dot{M}=0$ line shifts to the left. Food price unambiguously falls. This generates additional foreign exchange reserves to support industrial expansion. This is shown in figure (4a). Food price overshoots or undershoots depending on final effect on stock of money. If money supply falls (increase), food price undershoots (overshoots) and there is neither undershooting nor overshooting of food price if money supply is unchanged. In case of initial short run contractionary effect, money supply unambiguously rises and food price unambiguously overshoots. This is presented in the figure (4b). 
Figure 4a. Undershooting of ' $P_{f}$ ' with fall in ' $M$ '.

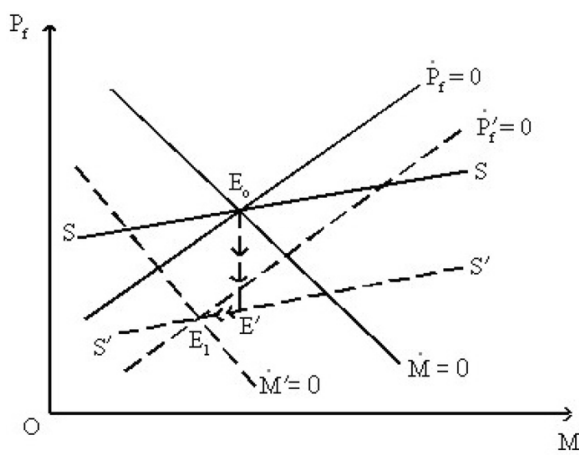

Figure 4b. Overshooting of ' $P_{f}$ ' with increase in ' $M$ '.

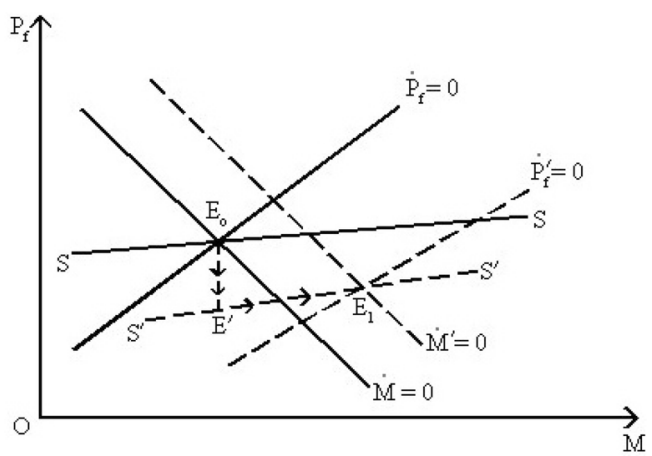

The steady state effects of a rise in food supply are -

$$
\begin{aligned}
& \left.\frac{d M}{d F}\right|_{L R}=\frac{-\theta_{4} \psi_{2}+\theta_{2} \psi_{4}}{\Omega} ? \\
& \left.\frac{d P_{f}}{d F}\right|_{L R}=\frac{-\theta_{1} \psi_{4}+\theta_{4} \psi_{1}}{\Omega} ?
\end{aligned}
$$

3) Devaluation : Devaluation entails contractionary effects which has been already examined in section 3.1.5. An important result of the paper is that, this short run contractionary effect of devaluation is completely reversed in the long run. It follows from equation (3) that -

$\hat{P}_{y}=\beta_{2} . \hat{e}$, where $\beta_{2}=\frac{e \cdot a_{m}}{P_{y}}$, cost share of intermediate input. Clearly, $\hat{P}_{y}<\hat{e}$. In the long run, industrial output must rise and food price will also rise. This can be explained as follows -

First we note that in the long run rate of interest remains unchanged and hence private investment remains invariant to devaluation. Therefore demand for industrial output can change only through change in private consumption which requires adjustment in internal terms of trade. Now suppose that industrial output falls. From the trade balance equation, it follows that $P_{f}<\hat{e}$. From the industrial balance equation, it follows that $\hat{P}_{y}<P_{y}$. Since $\hat{P}_{y}<\hat{e}$, we get a contradiction.

Similarly, industrial output cannot remain unchanged. In case of unchanged output level, trade balance equation gives $\hat{P}_{y}=\hat{e}$ while industrial balance equation gives $\hat{P}_{f}=P_{y}$. Since $\hat{P}_{y}<\hat{e}$, we get a contradiction.

Since output level rises, we have $\hat{P}_{y}<P_{f}<\hat{e}$. Since demand for money goes up, 
real money supply rises which requires $\hat{M}>P_{y}$. The rise in money supply can be explained in terms of trade surplus that devaluation generates. In terms of long run dynamics, food price unambiguously overshoots. On impact food price may either fall or rise or remain unchanged, but in the long run food price unambiguously rises. Thus the internal terms of trade moves in favour of the agricultural sector.

The steady state effects of devaluation are -

$$
\begin{aligned}
& \left.\frac{d M}{d e}\right|_{L R}=\frac{-\theta_{5} \psi_{2}+\theta_{2} \psi_{5}}{\Omega}>0 \\
& \left.\frac{d P_{f}}{d e}\right|_{L R}=\frac{-\theta_{1} \psi_{5}+\theta_{5} \psi_{1}}{\Omega} ?
\end{aligned}
$$

\section{Conclusion}

In this paper, we have attempted to address issues pertaining to macroeconomic implications of agricultural trade liberalization in terms of a dependent economy monetary framework, in which the industrial sector is a non-traded sector and the agricultural sector is the traded sector. The dependence of the industrial sector on the agricultural sector is two-fold, namely provision of wage-goods and that of foreign exchange. Since the industrial production is heavily import dependent in most of the developing countries, which are subject to balance of payment difficulties, the WTO provisions which offer external market for agricultural exports, acquire special dimensions. Developing countries have been liberalizing their trade regimes that have implied more favourable treatment of the agricultural sector. Multilateral liberalization primarily implies reduced protection of agriculture in the developed countries. Clearly, the developing countries that are potentially net exporters of agricultural products stand to gain.

This paper has developed a long run dependent economy macromodel with a clear focus on intersectoral interlinkage in a dual economy. The paper is actually based on a monetary dual economy model by Moutos and Vines. We have extended their model by incorporating specific details of international trade. In the long run, the steady state variables are food price and stock of money. Food price adjusts instantaneously to clear asset market while money stock changes continuously in response to current account deficit. The model in this paper offers saddle path stability of the system.

The different comparative static exercises attempted in this paper indicate that 
short run and long run effects of shocks are significantly different. For example, devaluation is contractionary in the short run but expansionary in the long run. Identical conclusion holds for rise in the marketable surplus of food. Again the long run expansionary effect of rise in government expenditure is less compared to its short run effect due to crowding out through fall in food price. Hence, the clear policy message is that short run effect is not a reliable guide to design of macroeconomic policy.

The paper can be extended in different direction. The long run issues of capital accumulation in the traded agricultural sector and export dynamics through J-curve effect can be easily accommodated. In the short run capital stock in the agricultural sector is fixed, but over time it could change in response to terms of trade movement. ${ }^{13}$ Capital accumulation in the agricultural sector responds positively to terms of trade movement in favour of the agricultural sector. This extension will significantly change long run effects of shocks. In particular, we note that increase in government expenditure on industrial product would reduce agricultural production in the long run, since it causes terms of trade movement against the agricultural sector. The model can also be extended to include flexible exchange rate on current account. This extension is theoretical imperative in the context of contemporary trends towards greater exchange rate flexibility and current account convertibility. Moreover, the model in our paper is based on sticky wage. In a more complicated model than ours, wage dynamics can be accommodated.

\section{Acknowledgmetns}

We are grateful to professor Arup Mallick and an anonymous referee of this journal for valuable comments. However, the usual disclaimer applies.

Received 27 January 2004, Accepted 4 July 2004

\section{References}

Badao, A and Martin, W. (1993) Implications of Agriculture Trade Liberalization for the Developing Countries, Agricultural Economics, 8, pp.313-343.

Bhaduri, A and Skarstein, R. (2001) Effective Demand and the Terms of Trade : A Kaldorian Perspective (mimeo), Indian Institute of Management, Kolkata.

${ }^{13}$ See Rattso(1989) 
Bose, A. (1989) Short Period Equilibrium in a Less Developed Economy, in Mihir Rakshit (ed.), Studies in the Macroeconomics of Developing Countries, Delhi, Oxford University Press.

Buffie, E. (1986) Devaluation, Investment and Growth in LDCs, Journal of Develop-ment Economics 20, pp.361-379.

Desai, B.M. (2002) Terms of Trade, Trade and Technical Change : Strategies for Agricultural Growth in EPW, February 23, 2002, pp.801-804.

Dutt, A.K. (1990) Growth, Distribution and Uneven Development, Cambridge : Cambridge University Press.

Frankel, J.A. (1986) "Expectations and Commodity Price Dynamics : The Overshooting Model." American Journal of Agricultural Economics, 344-8.

Gilbert, C. (1985) "Optimal and Competitive Storage Rules, the Gustafson Problem Revisited.” Department of Economics, Queen's University, Kingston (mimeo).

Haug, R and Oygard, R. (1999) Trade Liberalization in Agriculture: Consequences for Growth, Poverty Reduction and Environment in Developing countries, Center for International Environment and Development Studies, Agricultural University of Norway.

Hertel, T., Anderson, K., Francois, J., and Martin, W. (2000) Agriculture and NonAgricultural Liberalization in the Millennium Round Centre For International Economic Studies, Policy Discussion Paper, No.0016.

Kaldor, N. (1939) "Speculation and Economic Stability." Review of Economic Studies, 7, $1-27$.

Martin, W., and Winters L.A. ed. (1995) The Uruguay Round and The Developing Economics, World Bank Discussion Paper 307 World Bank, Washington, DC.

Moutos, T., and Vines, D. (1992) “Output, inflation and commodity prices", Oxford Economic Papers, 44 pp. 355-372.

Nag, N.R. and Ghosh, P.P. (2003) Industry-Agriculture Interlinkage, Agricultural Trade liberalization and Supply constraints : A Post WTO Perspective. Indian Economic Review, Vol.XXXVIII, No.2,2003, pp. 235-251.

Rakshit, M. (1982) The Labour Surplus Economy, Delhi : Macmillan.

Ratts, F, J. (1989) Macrodynamic Adjustment Mechanisms in a Dual Semi-Industrialized Economy, Journal of Development Economics, 30, pp.47-69.

Taylor, L. (1983) Structuralist Macroeconomics : Applicable Models for the Third World, New York, Basic Books.

(1991), Income Distribution, Growth and Inflation : Lectures of Structuralist Macroeconomic Theory, Cambridge, MMA : MIT Press. and Krugman, P. (1978) Contractionary Effects of Devaluation, Journal of International Economics, 8, pp.445-456.

Wijnbergen, S. (1986) Exchange rate Management and Stabilization Policies in Developing countries, Journal of Development Economics, 23, pp.227-47. 


\section{Mathematical Appendix}

1. Derivation of Saddle path :

The initial steady-state equilibrium solutions for $M, P_{f}$, denoted by $M_{l}, P_{f 1}$, say are obtained by solving

$$
\left[\begin{array}{c}
\dot{M} \\
\dot{P}_{f}
\end{array}\right]=\left[\begin{array}{ll}
\theta_{1} & \theta_{2} \\
\psi_{1} & \psi_{2}
\end{array}\right]\left[\begin{array}{l}
\bar{M}-M_{1} \\
\bar{P}_{f}-P_{f_{1}}
\end{array}\right]
$$

Now suppose that at time 0 it is announced that a parameter (For example, G, or $\mathrm{F}$ or e) are to increase, at time $\mathrm{T} \geq 0$. The new steady states after the shifts have occurred are specified by

$$
\left[\begin{array}{c}
\dot{M} \\
\dot{P}_{f}
\end{array}\right]=\left[\begin{array}{ll}
\theta_{1} & \theta_{2} \\
\psi_{1} & \psi_{2}
\end{array}\right]\left[\begin{array}{l}
\bar{M}-M_{1} \\
\bar{P}_{f}-P_{f_{2}}
\end{array}\right]
$$

As long as the shifts are additive, so that the coefficients $a_{i j}$ remain unchanged between the two regimes, the eigenvalues $\lambda_{1}, \lambda_{2}$ say of (1) and (2) are identical. For simplicity and without loss of generality, we shall assume that they are real. The fact that the dynamics are described by a saddle point means that the product

$$
\lambda_{1} \lambda_{2}=\theta_{1} \Psi_{2}-\theta_{2} \Psi_{1}<0
$$

We shall assume $\lambda_{1}<0, \lambda_{2}>0$. In order to ensure stability, one of variables say $\mathrm{P}_{\mathrm{f}}$, must be a jump variable, while the other $\mathrm{M}$, is assumed to evolve continuously at all times.

Over the period $0<\mathrm{t} \leq \mathrm{T}$, before the shifts have occurred, the solutions for $\mathrm{M}, \mathrm{P}_{\mathrm{f}}$ are of the form

$$
\begin{gathered}
M=M_{1}+A_{1} e^{\lambda_{1} t}+A_{1} e^{\lambda_{2} t} \\
P_{f}=P_{f_{1}}+\left(\frac{\lambda_{1}+\theta_{1}}{\theta_{2}}\right) A_{1} e^{\lambda_{1} t}+\left(\frac{\lambda_{2}+\theta_{1}}{\theta_{2}}\right) A_{2} e^{\lambda_{2} t}
\end{gathered}
$$

Note that because $\lambda_{i}$ are eigen values 


$$
\frac{\lambda_{i}-\theta_{1}}{\theta_{2}}=\frac{\psi_{1}}{\lambda_{i}-\psi_{2}}, \quad i=1,2
$$

in which case (3.2) can be rewritten equivalently as

$$
P_{f}=P_{f_{1}}+\left(\frac{\psi_{1}}{\lambda_{1}-\psi_{2}}\right) A_{1} e^{\lambda_{1} t}+\left(\frac{\psi_{1}}{\lambda_{2}-\psi_{2}}\right) A_{2} e^{\lambda_{2} t}
$$

Likewise, for the period t $\breve{\mathrm{S}} \mathrm{T}$, after the shifts have occurred, the solutions for $\mathrm{M}$, $P_{f}$ are

$$
\begin{gathered}
M=M_{2}+A_{1}^{\prime} e^{\lambda_{1} t}+A_{2}^{\prime} e^{\lambda_{2} t} \\
P_{f}=P_{f_{2}}+\left(\frac{\lambda_{1}-\theta_{1}}{\theta_{2}}\right) A_{1}^{\prime} e^{\lambda_{1} t}+\left(\frac{\lambda_{2}-\theta_{1}}{\theta_{2}}\right) A_{2}^{\prime} e^{\lambda_{2} t}
\end{gathered}
$$

Now convergence requires that as $\mathrm{t} \rightarrow \infty . A_{2}^{\prime}=0$, so that

$$
\begin{gathered}
M=M_{2}+A_{1}^{\prime} e^{\lambda_{1} t} \\
P_{f}=P_{f_{2}}+\left(\frac{\lambda_{1}-\theta_{1}}{\theta_{2}}\right) A_{1}^{\prime} e^{\lambda_{1} t}
\end{gathered}
$$

Eliminating from equation (5.1) and (5.2), we get

$$
\left(P_{f}-P_{f_{2}}\right)=\left(\frac{\lambda_{1}-\theta_{1}}{\theta_{2}}\right)\left(M-M_{2}\right)
$$

or, equivalently as

$$
\left(P_{f}-P_{f_{2}}\right)=\left(\frac{\psi_{1}}{\lambda_{1}-\theta_{1}}\right)\left(M-M_{2}\right)
$$

Equation (6.1) or (6.2) describes the equation of saddle path. 